\title{
Who works in family planning clinics?
}

\author{
FLEUR FISHER, ROSEMARY KIRKMAN, CONAMORE SMITH
}

\section{Introduction}

The training and future of community health doctors have been the subject of much controversy. Comprehensive national statistics are available relating to the patients seen and the work done, but there is a dearth of information about the doctors themselves-their qualifications, their other interests, and their degree of commitment to community health work. Almost all the original core of public health doctors who lost their career structure in 1974 did some child health work. From 1974 onwards, however, doctors working in Family Planning Association clinics were integrated into the National Health Service. Many have continued to be employed on a sessional basis without contracts and have therefore often been unknown to personnel officers other than by age, sex, and number of sessions worked. We have attempted to fill some of the gaps in knowledge about present providers of the service.

\section{Method}

One senior doctor known to be active in family planning clinic work for each health district of the United Kingdom was recruited by personal contact through membership of a family planning doctors group (with notification of the district medical officer). These doctors were used as coordinators, and were asked to provide a list of the names of all doctors working in family planning clinics in their own health district during January 1984. Questionnaires were sent to the coordinators to be distributed to the doctors concerned. The coordinators were responsible for collecting the forms and returning them to BMA House for computer coding. Family planning clinic work was defined as including contraception and counselling for abortion, female sterilisation, and vasectomy, but not specialist psychosexual sessions. Doctors employed in more than one health district were asked to complete only one form, but to specify on it each post held. Whole time equivalents were obtained by counting each session as one tenth full time and dividing by the number (21) of working days in January 1984. The inquiry covered qualifications, the grade and basis of employment, and length of family planning sessions. Information about the nature and amount of other medical work done by these doctors in

Macclesfield District General Hospital, Macclesfield SK10 3BL

FLEUR FISHER, MB, DRCOG, senior clinical medical officer in family planning and cytology

Community Services Unit, Sheffield S1 2PJ

ROSEMARY KIRKMAN, MB, FRCOG, principal medical officer in family planning and related services

Raymede Health Centre, London W10 5SH

CONAMORE SMITH, MB, BS, senior clinical medical officer in family planning

Correspondence to: Dr Fisher, Macclesfield District General Hospital, West Park Branch, Prestbury, Macclesfield SK 10 3BL. community, hospital, general practice, or other organisations was also requested. There was one omission-we did not ask the sex of the doctor.

\section{Results}

We circularised 221 health districts and health boards in the United Kingdom with 3542 questionnaires. A total of 2214 usable questionnaires was returned for coding and computer processing. A manual sort, however, identified 124 cases where no family planning sessions had been undertaken in January 1984 and this paper is based on the remaining 2090 returns. Some respondents failed to complete certain parts of the questionnaire and these are referred to as "unspecified." For example, 70 postholders (63 respondents) did not indicate the district health authority for which family planning work was undertaken, and 31 failed to provide information on the numbers of sessions worked during January, although indicating that such work was undertaken. The coordinating doctors reported 3542 posts in community family planning clinics in January 1984. As many doctors work in more than one district we cannot give a figure except in terms of posts.

Of our 2090 respondents, $1646(78.8 \%)$ worked in family planning clinics for only one district health authority; $353(16.9 \%)$ held posts with two different district health authorities, $66(3 \cdot 2 \%)$ with three, and $25(1 \cdot 2 \%)$ with more than three districts. Counting doctors for each district in which they worked (as in Department of Health and Social Security statistics) gives a total of 2555 posts for the 2027 individuals and a $72 \%$ response rate compared with the 3542 posts reported by the coordinators.

Just under half $(49 \cdot 8 \%)$ of the 2594 posts for which information was supplied were for four family planning sessions a month or less. The mean number of sessions per post was seven, and only 106 respondents $(4 \cdot 1 \%)$ worked half time or more in family planning clinics.

A total of 17715 family planning clinic sessions were reported by the 2027 doctors, representing $421 \cdot 8$ whole time equivalent doctors (table I). These sessions exclude time spent on related subjects, such

TABLE I-Doctors in whole time equivalents (wte) working in community family planning services

\begin{tabular}{lc}
\hline & No (wte) \\
\hline England & \\
Northern & $22 \cdot 76$ \\
Yorkshire & $25 \cdot 66$ \\
Trent & $32 \cdot 83$ \\
East Anglia & $11 \cdot 76$ \\
North West Thames & $39 \cdot 93$ \\
North East Thames & $33 \cdot 38$ \\
South East Thames & $20 \cdot 38$ \\
South West Thames & $30 \cdot 98$ \\
Wessex & $20 \cdot 31$ \\
Oxford & $19 \cdot 17$ \\
South Western & $22 \cdot 88$ \\
W'est Midlands & $32 \cdot 78$ \\
Mersey & $17 \cdot 28$ \\
North Western & $31 \cdot 83$ \\
London Postgraduate Medical School & $0 \cdot 38$ \\
Scoltand & $34 \cdot 81$ \\
W'ales & $14 \cdot 60$ \\
Northern Ireland & $10 \cdot 05$ \\
\hline
\end{tabular}


as psychosexual counselling, well woman clinics and cytology, administration, teaching, and domiciliary family planning. The whole time equivalent figure of other community employment, excluding child health, school health, and immunisation, was $96 \cdot 2$.

Forty per cent of posts were reported as held on a contract basis and $60 \%$ on a sessional basis. Doctors designated senior clinical medical officers reported that 492 posts were on contract, 116 were sessional, and 10 unspecified. A substantial number of respondents did not report the length of paid session, but of those who did (a total of 2170 posts) an equal proportion ( $49 \%$ in each case) were of two to two and a half hours' duration and three to three and a half hours' duration. The overwhelming majority reported that these hours did not include administrative or travelling time. There was a clear indication that senior clinical medical officers tended to work longer hours than clinical medical officers.

Of the 2090 respondents, 344 worked only in family planning clinics, and a further 737 worked only or predominantly in community health, predominantly being defined as community sessions exceeding sessions worked during the month in other areas. Of the 1746 other doctors who did not work solely in family planning clinics, 1130 held one other post; 400 two other posts; 133 three other posts; 50 four other posts; 17 five other posts; and 16 more than five other posts.

The total number of identifiable posts held by respondents apart from their work in family planning was 2694 , of which $1073(39 \cdot 8 \%)$ were in community health, $550(20.4 \%)$ in the hospital service, and $1070(39 \cdot 7 \%)$ elsewhere. Of these 1070,782 were in general practice. There was a tremendous variety in the type of other work done. Community employment included 517 posts in child health, school health, and immunisation as well as subjects related to family planning. Hospital activities were diverse, including 84 posts in obstetrics, 56 in genitourinary medicine, 38 in gynaecology, 22 in paediatrics, 17 in ultrasound, but 311 in other specialties apparently unrelated to family planning.

The qualifications held by the respondents are set out in table II.

TABLE II-Qualifications held by respondents relating to family planning

\begin{tabular}{lr}
\hline Qualification & No (\%) \\
\hline Family Planning Association (ordinary certificate) & $1373(65 \cdot 7)$ \\
Family Planning Association (intrauterine contraceptive device certificate) & $1303(62 \cdot 3)$ \\
Joint Committee of Contraception (ordinary certificate) & $915(43 \cdot 8)$ \\
Diploma of the Royal College of Obstetricians and Gynaecologists & $664(31 \cdot 8)$ \\
Membership of the RCOG & $132(6 \cdot 3)$ \\
Fellowship of the RCOG. & $12(0 \cdot 57)$ \\
Membership of the Royal College of General Practitioners & $152(7 \cdot 3)$
\end{tabular}

The Family Planning Association certificates must have been obtained more than 10 years previously. The Joint Committee of Contraception certificate, which was introduced in 1974, was held by 446 doctors. They did not have a Family Planning Association qualification and must therefore have trained during the past 10 years. Thirty three of the 152 doctors with the membership of the Royal College of General Practitioners held a family planning instructing doctor's qualification. Forty respondents, scattered over many health districts, had none of the recognised family planning qualifications. A few doctors held other qualifications, including Diploma in Child Health, Diploma in Public Health, Diploma in Anaesthetics and the fellowship of the Royal College of Surgeons.

\section{Discussion}

The method chosen for identifying doctors working in community family planning, by contacting coordinating doctors for each district, was relatively inexpensive and proved practicable in giving a good response rate. Without the good will and local knowledge of well motivated coordinating doctors it would have been impossible to conduct a nationwide survey in this way.

The Department of Health's 1983 survey of community clinical medical staff, with an $80 \%$ response rate from the districts, gave a total number of family planning posts excluding locum and occasional sessional staff of 1964 - that is, $56 \%$ of the 3478 reported by our coordinators in England, Wales, and Scotland. ${ }^{1}$ This represents a whole time equivalent number of $294 \cdot 7$ - that is, $71 \%$ of the $411 \cdot 75$ counted on our survey, excluding Northern Ireland. This would support our impression that the non-responders in our survey were generally those with less time committed to family planning work.

Family planning clinics receive approximately 1.5 million visits a year, and provide the full range of contraceptive methods as well as undertaking most of the specialist family planning training. ${ }^{2}$ Family planning doctors also teach students and postgraduate nurses. The wealth of experience in the delivery of birth control care, as well as the varied population of clinic patients, provide an invaluable basis for clinical research and training in the specialty. The survey shows that this training is available in the clinics. Of the 987 instructing doctors ever recognised by the Joint Committee of Contraception, 753 are shown by this survey to be working in community health family planning clinics. The marked proportion of family planning doctors who have been trained since the Joint Committee of Contraception qualification was established shows the continuing importance of this training function, which should continue as general practitioners increasingly train to provide this skill in their surgeries.

The survey also allowed us to analyse the other medical work undertaken by doctors working in family planning clinics. Although, as might have been expected, many posts (nearly $40 \%$ ) were in other branches of the community health services, $20 \%$ were in various hospital specialties and no less than $29 \%$ were held by general practitioners working outside their own practices. The benefits brought to family planning from these differing disciplines and the skills taken from it can only be suggested by these figures.

In looking at the length of sessions we found that our results reflect the chaotic position in terms and conditions of service of this group of doctors, many of whom have higher qualifications in family planning. Nearly $19 \%$ of the doctors doing senior work reported that they did not have a contract. Thus they were denied security of employment, holiday, and sick pay, as well as maternity and pension benefits. There is clearly a risk that the continuing lack of application of standard terms and conditions (though these were negotiated nationally in 1974), coupled with the lack of a coherent career structure ${ }^{3}$ or of recognition of specialty status, is likely to be a major disincentive both for those who would like to work full time as family planning specialists and for those who seek to combine this with other medical work.

We should like to thank the Central Committee for Community Medicine and Community Health for funding the survey; Dr Audrey Ward of the Medical Care Research Unit, Sheffield, for helping us to design the questionnaire; and Mrs Joan Sherratt for her organisational and secretarial skills.

\section{References}

1 Department of Health and Social Security. Community medicine and community health service medical staff. England and Wales regional tables. London: DHSS, 1984

2 Department of Health and Social Security. Statistics Research Division. Survey of community health

3 Central Committed for Community Medicine. Career structure and training for community health doctors. Report of the community health doctors subcommittee. London: BMA, 1982.

(Accepted 25 fuly 1985) 